\title{
Microbial Communities Inhabiting Gas Storage Sites: Analysis of Diversity and Function at Depth
}

ASHLEY GROSCHE1*, SELMA ABDELHAK 1, MARIA LUDWIG1, , MOHAMED JEBBAR 1, LoÏS MAIGNIEN1,2*

1Univ Brest (UBO), CNRS, IFREMER, Laboratoire de Microbiologie des Environnements Extrêmes, F-29280, Plouzané, France

(*correspondence: Ashley.Grosche@univ-brest.fr) (*correspondence: Lois.Maignien@univ-brest.fr) 2Josephine Paul Bay Center, MBL, Woods Hole, MA, USA

\section{Sequestration and Storage of $\mathrm{CO}_{2}$ Waste}

Carbfix is an industrial carbon capture and storage (CCS) operation which relies on the injection of $\mathrm{CO}_{2}$-charged groundwater into basaltic formations, resulting in the precipitation of carbon in mineral form for permanent storage in the subsurface [1]. Up to great depths, basaltic crust is host to native microbial populations which are subject to acidifying, oxidizing conditions during injection [2]. Our analysis of the subsurface microbial communities inhabiting gas storage sites identifies distinct communities partitioned by sample origin and depth. Several dominant taxa were identified that could be ecologically relevant to subsurface operations such as Candidatus Desulforudis (a deep biosphere chemolithoautotroph), Candidatus Tenderia (a potential electroautotroph), and Desulfotomaculum, Hydrogenophaga, and Paracoccus (taxa with species capable of oxidizing hydrogen gas, with some species also capable of utilizing carbon dioxide). Several of these taxonomic groups have cultivates capable of oxidizing reduced sulfur and iron species (Sulfuricella, Thiobacillus). This study determines depth-specific biomarkers for gas injection sites, reconstructs subsurface metagenome assembled genomes (MAGs) including several Candidatus Desulforudis audaxviator MAGs, and details the isolation of a novel, Fe2+-oxidizing, $\mathrm{CO}_{2}$-fixing aerobic bacterium isolated from a gas storage monitoring well 800 meters below surface.

[1] Gislason (2014) Science 344, 373-374.

[2] Trias (2017) Nature communications 8, 1-14. 